Article

\title{
Experimental Study on the Utility and Future of Collaborative Consumption Platforms Offering Tourism Related Services
}

\author{
Joan-Francesc Fondevila-Gascón ${ }^{1}$ (D), Gaspar Berbel ${ }^{2}$ and Mònica Muñoz-González ${ }^{2, *}$ \\ 1 Escola Universitària Mediterrani (UdG), CESINE, UPF, URL, UOC, Euncet-UPC, EAE-UPC, UB, UAB, \\ CECABLE, Rocafort, 104, 08015 Barcelona, Spain; jf.fondevila@mediterrani.com \\ 2 Escola Universitària Mediterrani (UdG), Rocafort, 104, 08015 Barcelona, Spain; \\ gaspar.berbel@mediterrani.com \\ * Correspondence: monica.munoz@mediterrani.com; Tel.: +34-93426-98-22
}

Received: 31 January 2019; Accepted: 20 March 2019; Published: 25 March 2019

\begin{abstract}
The present study analyzes four well-known online platforms used in the tourist industry for travelling, accommodation, eating, and touring (Blablacar, Airbnb, Eatwith, and Trip4real). The objective is to analyze the utility of the portals, intentions for future use and recommendation (prospective), and reputation. The method is an experimental design with a control group and experimental group. Within both groups, three scales were applied. The results indicate clear differences between the control and experimental groups, valuing above all the utility and the intent to use again when the group is exposed to the portals from a needs-based situation (experimental group). The analysis demonstrates a factorial structure that validates the model. At the same time, the results indicate a greater interest in using Trip4Real over BlaBlaCar. Generation Z, the youngest generation, shows greater confidence in the services and greater interest in using tourism related collaborative consumption platforms in the future.
\end{abstract}

Keywords: collaborative consumption; peer to peer; $\mathrm{X}$ and $\mathrm{Y}$ generations; consumer; prosumer; Internet; reputation capital

\section{Introduction}

The new social or collaborative economy is based on a P2P (peer-to-peer) business model that is quickly growing and gaining ground. Botsman affirmed that the market value for peer-to-peer business is around 26 million US dollars [1]. There are more than 5000 organizations that develop these kinds of collaborative consumption (CC) activities [2].

Currently, the growth in services and platforms for collaborative consumption-or the sharing economy [3,4] - is evident, articulated around individuals that share interests, needs, a life philosophy, and that connect through a system of social connections and management, with a consequent reduction in marginal costs. This dynamic is based on the logic of sharing resources and materials, including the creation, production, distribution, and exchange of consumer goods and services for people and organizations [5]. This movement arises from social and technological changes that prioritize sharing over owning: "The traditional method of sharing, exchanging, loaning, renting, or gifting is redefined through technology and communities" [4], imitating exchanges that used to be performed face to face, along with the combined factor of the capacity to generate confidence between strangers [1].

Industrial meetings and activities need to prepare themselves for the change that the collaborative economy implies for the new generation. In a presentation of new trends, generation Z-born after 1982, also the millennials-is modifying the industry along with the revolution in CC led by companies, like Airbnb and Uber. This generation will convert the industry into something 
unrecognizable. The collaborative economy, based on exchange, will assert itself. Workers are tired of corporate meetings and are looking for something different, more unusual, and memorable; many have already travelled to cities, like London, Paris, Amsterdam, and Berlin, where an alternative vision and paradigm is being applied. The industry is headed towards a paradigm based in corporate confidence; if it is high, the consumption of its products and services will increase.

The emergence of this kind of economy is not without difficulties, due to legal aspects outside the normative framework that are applicable to traditional types of activities. Some countries are already regulating them, like other technological sectors, such as cable [6,7], HbbTV (Hybrid broadcast broadband TV) [8], or smartphones $[9,10]$, though conflict between the two types of economies persists.

In this article, we analyze four online platforms about travelling, accommodation, eating, and touring (Blablacar, Airbnb, Eatwith, and Trip4real) with the goal of observing the utility of the portals, intentions for future use and recommendation (prospective), and reputation.

In the European Parliament, there is a ruling $(2014 / C$ 177/01) on collaborative or participative consumption, which sets out a series of recommendations. It indicates the necessity for the pertinent institutions, after careful study, to regulate and order certain practices, with the goal of establishing the rights and responsibilities for the implicated parties. This ruling is situated along the lines established by Europe 2020. The equation credit + advertising + individual property $=$ hyper-consumption is currently being transformed into reputation + community + shared access $=$ shared or collaborative consumption. Bartering, renting, group purchasing, do-it-yourself, buying locally, and buying second-hand are increasing tendencies for European consumers (Cetelem, 2013-in the ruling 2014/C $177 / 01)$.

Reputation capital can act as a second currency whose value resides in offering confidence: Reputation capital is emerging as a fundamental pillar for the 21st century economy in that it means that "word-of-mouth" power is being projected onto the viral capacity of the internet society. The ruling also gathers together indicators that denote the impact that reputation has, such as the growth rate for these types of services, which is currently at about $25 \%$ annually.

Seventy-five percent of the Spanish population between the ages of 16 and 55 are internet users, of which $81 \%$ use social networks [11], such as Facebook, WhatsApp, Twitter, YouTube, and Instagram (100\%, 94\%, 92\%, 84\%, and 83\% respectively); among these internet users, 65\% claim that social networks have influenced them at the time of making a purchase.

The systems within which these types of activities can be broken down into three categories [1]: Product-service (a system in which the user pays, but does not acquire the property); redistribution of goods (used goods are transferred or exchanged); collaboration (interests and life philosophies are shared; non-tangible resources are transferred or exchanged, whether this is time, space, skills, or money).

CC activities have evolved, moving from simply B2C (business to consumer) models, in which the business acquires and then rents something to the consumer, toward P2P [12,13], consumer to consumer, models, in which the community provides the goods in exchange, normally, for a small benefit from the transaction.

Within the tourist sector, CC business linked to the transportation of people, accommodation, and gastronomy have increased. Indeed, within the sector, they have acquired a high level of prominence such that they have arguably led to considerable consequences for the sector. Uber and Airbnb, the most popular marketplace, are examples focused on accommodation and private transportation. Within the field of holiday accommodations, the home exchange sector is also becoming a trend for the tourist market and its future [14].

The importance of eWOM (electronic word-of-mouth) and metrics is both evident and increasingly subject to study [15]. This is defined as the communication between two people about products, services, brands, or organizations. The tourist industry is extremely subject to eWOM. Its effects on business results within the tourism sector are pervasive [16-21]. 
An association [22] studied the CC companies currently operating in Spain. They found that the most transparent were Eatwith, Etecé, Huertos compartidos, Homeaway, Intercambio de casas, Nolotiro, Segundamano, Timerepublik, Trip4Real, Ulule, and Verkami. Among the aspects that were analyzed, the following stood out: Functionality and user-friendliness (the tools for communicating with other users were analyzed to see if they are intuitive, easy to use, and facilitate contact); confidence and virtual reputation (confidence increases if users are not allowed to comment unless they are registered, if the platform has verification systems to ensure the authenticity of the comments, and/or if it shows photographs); rules and policies (the platform is safer for communication and transactions if users who improperly use the platform can be blocked or reported); and community fingerprint (when there is a redistribution of wealth or a commitment to a social or environmental cause).

Online CC platforms have demonstrated that they can be efficient and have growth potential, though these are not always managed responsibly. The study highlights the most efficient CC companies-with ratios over 10,000 users per employee-Homeaway, Segundamano, Verkami, and Nolotiro.

The research measures the approval of some CC platforms. The majority of the research done on the possible approval of technological types of services collect individual perceptions based on beliefs or evaluations of the perceived utility, the ease of use, and the perceived pleasure or enjoyment, in order to understand the approval [23]. The perceptions and evaluations can be influenced [24].

The perceived use and ease of use are key beliefs in the technological acceptance model (MAT) that determine the future intention of users in the use of certain types of technological services $[25,26]$.

User beliefs or behaviors change when dissonance exists between their previous thoughts and the observed reality. When they experience the possible functions or advantages, they revise their pre-conceived ideas and the dissonance diminishes $[27,28]$. The cognitive dissonance theory is not the only one that can explain the effect of learning about the functions and advantages of a service, rather the confirmation of expectations can also be used. Research in marketing and psychology demonstrates that the trial and error of products is a key aspect in the formation of beliefs and attitudes. Testing a product or service allows for types of approaches or cognition towards the said service. The test-before-buying model is widely used for technological products. Previous or real-world experience of a service generates a better evaluation of its utility and builds beliefs that are more solid than publicity in generating attitudes that are stronger and more consistent. Beliefs based on direct experience are better predictors of attitude-behavior than those based on indirect experience.

\section{Materials and Methods}

This study is experimental. In the present research, an experimental variable is introduced, "Group", in which subjects are allowed, or not, to have a direct experience with the CC service, based on the recreation of a specific type of need. This variable allows for the evaluation of the effect that previous experience of the technological service has on its subsequent evaluation and future attitudes or behavior.

The research was conducted in the season of 2015-2016 (the collection and processing of data was undertaken between October 2015 and January 2016). The respondents were selected in the marketing degree. The controlled variable statement was: An initial situation that could be either "without a goal (control)" or "with a goal (experimental)", as well as a set of evaluative type effect variables, in relation to the utility and behavioral intention after gaining knowledge or use of the platforms, Blablacar, Airbnb, Eatwith, and Trip4real.

The following hypotheses were formed:

H1: Members of the millennial generation demonstrate higher interest and confidence in online platforms and comments than those of generation $X$.

$\mathrm{H} 2$ : The influence of eWOM (use-value of the comments, and the intent to act as a prosumer) is higher in generation $\mathrm{Z}$ than in the millennial and $\mathrm{X}$ generations. 
H3: The influence of eWOM (use-value of the comments and the intent to participate or to comment-prosumer) constitutes a factor within the general scale.

H4: The "group" variable (the experimental situation, with the goal of fulfilling a supposed need) will increase interest and confidence along with the intent to use for all platforms.

The sample type was intentional based on quotas for age and sex. The final sample size was $n=222$. The sample error was $6.7 \%$. $58 \%$ of the participants were women; the average age was 28.6 years old (Confidence Index 95\%: from 26.9 to 30.4 years old), and $18 \%$ of participants were from generation X (born before 1982). The questionnaire used was comprised of 9 scales asking about the level of interest and confidence in the platforms analyzed, as well as the future behavioral intentions for them, on a scale of 1 to 5 . The research team was comprised of 12 students in their fourth year of a marketing degree, in a class on qualitative and prospective research. They had been previously instructed by the researchers.

The procedure that was followed in the collection of the data and the assignation of situations is as follows:

1. The assignation to the control or experimental group was random (by flipping a coin, heads = experimental, tails $=$ control). The experimental group was directly assigned to those participants who reported already being users of the chosen platforms.

2. A laptop was used to show the participants the platform. Participants were advised that they had five minutes to explore the site.

3. The platform's function was explained (Blablacar: To share a private car and the related costs of the trip; Airbnb: To rent apartments, houses, or rooms; Eatwith: To dine in the private home of someone who knows how to cook or is a professional; Trip4real: To be shown a new place or city by a local).

4. The control group was instructed to explore the page and to find out how it works, what options or possibilities it offers, to look for comments left by other users, find out how to pay for or contract the service, and to find out how to sign up. The researcher observed the participants' activity and ensured that they completed each step. In the case of those participants with little experience/aptitude, the researcher aided them in their exploration, as it was important that all the steps were completed. If the time limit expired before all steps were completed, the researcher demonstrated the different steps, never-exceeding a two-minute grace period.

5. For the experimental groups, steps 2 and 3 were the same, while step 4 was different. The change is that this group must "imagine that they are already registered users" (the researcher logged in to the session with a user name and password). The participant must act as though they are registered users. The information given to the participant was similar to that of the control group) and were instructed to determine how the site functions, its possibilities, find comments from other users, the method of payment, and signing up. However, they were also given a challenge or 'goal' consisting in determining the use value of the site through a simulated experience. Thus, depending on the site assigned to each researcher, the task was:

- Blablacar: Participants must find a vehicle to take them to Bilbao next Saturday morning.

- Airbnb: Participants must find and apartment, house, or room in Bilbao for the next weekend.

- Eatwith: Participants must find a private home in Bilbao to have dinner in next Saturday night.

- Trip4real: Participants must find someone to show them either Bilbao or the surrounding area (a guided visit) for next Saturday.

6. Participants were required to fill in the online questionnaire on the site, evalua-lo.com.

The site that each researcher was assigned was chosen randomly. Each researcher presented only one site to the participants, who were also randomly assigned. The criteria for inclusion of the participants required that they be internet users, and be capable of using web browsers and making purchases. The assignment of the situations-control or experimental (without a goal or with) -was also randomly done for those who claimed no previous knowledge of the site. Those who claimed to already know or be a user were automatically assigned to the experimental group. 
We applied variance analysis models (MANOVA), in a design factorial of $2 \times 2 \times 2 \times 4$. The factors or variables were group (control or experimental), generation $(\mathrm{Z}$ or $\mathrm{X})$, gender (woman or man), and platform or site (Blablacar, Airbnb, Eatwith, and Trip4real). For models that did not indicate homogenous variances, a corrected $\mathrm{F}$ value was used.

For validation, we analyzed the internal structure, through the data reduction technique of principal components analysis (PCA), factorial analysis with the oblimin rotation method, and data reduction test, with Kaiser-Meyer-Olkin and Bartlett's test values.

\section{Results}

The level of previous knowledge of the sites differed depending on the site $\left(X^{2}=11.77, p=0.008\right)$. The most well-known to participants were Blablacar (69.5\% were familiar with the site) and Airbnb (63\% were familiar with the site), and the least were Eatwith ( $44.7 \%$ were familiar with the site) and Trip4real (44\% were familiar with the site).

In the variance analysis models (MANOVA), the analysis was undertaken for each of the nine variables of the evaluative or intentional type. The following show the resulting models, once they had been refined, in an attempt to procure hierarchal and saturated models. In models with heterogeneous variances, we used a corrected $F$ value. The final, saturated model collected two significant principal effects: Platform and group. (Table 1) The level of interest was greater for the platform, Trip4real, compared to Eatwith, and in the experimental group (with a goal).

Table 1. Model with UTI2 "Level of interest of the participant in utilizing the platform".

\begin{tabular}{ccccc}
\hline & Y Variable & Source & F Value & $p$ \\
\hline \multirow{2}{*}{ UTI2 } & Level of interest in utilizing the platform & PLATFORM & 2.97 & 0.033 \\
& & GROUP & 33.58 & 0.0001 \\
\hline
\end{tabular}

The level of interest in using the platform was higher for the platform, Trip4real, between 0.31 and 1.7 (CI at 95\% for the difference) points more than those shown for Eatwith $(p=0.001)$. No significant difference was shown between the rest of the platforms.

The experimental group showed between 0.69 and 1.31 points more than the control group $(p>0.0001)$.

The final saturated, model collected the principal factors: Group and generation (significant principal effects) (Table 2). The level of confidence varied according to the group, as it was higher in the experimental group - with a goal-as well as in participants from generation Z. Generation $Z$ demonstrated between 0.96 and 1.96 points more than generation $X(p=0.003)$. The experimental group showed between 0.55 and 1.11 points more than the control group $(p<0.0001)$.

Table 2. Model with UTI3 "Level of confidence in the service".

\begin{tabular}{ccccc}
\hline & Y Variable & Source & F Value & $p$ \\
\hline \multirow{2}{*}{ UTI3 } & Level of confidence in the service & GROUP & 28.56 & 0.0001 \\
& & GENERATION & 4.40 & 0.037 \\
\hline
\end{tabular}

The final, saturated model collected the principal factor: Group (Table 3). The level of confidence in the payment system did not vary according to the platform or the generation. The level of confidence was higher in the experimental group, with a goal. The experimental group showed between 0.80 and 1.52 points more than the control group $(p<0.0001)$. 
Table 3. Model with UTI4 "Level of confidence in the payment system".

\begin{tabular}{ccccc}
\hline & Y Variable & Source & F Value & $p$ \\
\hline UTI4 & Level of confidence in the payment system & GROUP & 19.04 & 0.0001 \\
\hline
\end{tabular}

The final, saturated model collected the principal factor: Generation (Table 4). The level of utility of the comments or online evaluations varied according to the generation, with $\mathrm{Z}$ reporting the highest level of utility.

Table 4. Model with UTI5 "Level of utility of the comments/online evaluations".

\begin{tabular}{ccccc}
\hline & Y Variable & Source & F Value & $p$ \\
\hline UTI5 & Level of utility of the comments/online evaluations & GENERATION & 5.36 & 0.021 \\
\hline
\end{tabular}

Generation Z demonstrated between 0.07 and 0.80 points more than generation $X(p=0.021)$.

The final, saturated model collected the principal factor: Group (Table 5). The level of utility of making or leaving comments or evaluations online varied depending on the group. It was higher in the experimental group, in which the level of utility was shown to be between 0.04 and 0.61 points higher than for the control group $(p=0.026)$.

Table 5. Model with UTI6 "Level of utility of making/leaving comments or evaluations online".

\begin{tabular}{ccccc}
\hline & Y Variable & Source & F Value & $p$ \\
\hline UTI6 & $\begin{array}{c}\text { Level of utility of making/leaving comments or } \\
\text { evaluations online }\end{array}$ & GROUP & 5.05 & 0.026 \\
\hline
\end{tabular}

The final, saturated model collected the principal factor: Group (Table 6). The intention of using the system again did not vary according to the platform or generation though it did vary according to the group. It was between 0.91 and 1.58 points higher for the experimental group, with a mission.

Table 6. Model with FUT1 "Intention of using the system again".

\begin{tabular}{ccccc}
\hline & Y Variable & Source & F Value & $p$ \\
\hline FUT1 & Intention of using the system again & GROUP & 52.58 & 0.0001 \\
\hline
\end{tabular}

The final, saturated and hierarchical model collected the principal factors Group and sex, and a significant interaction factor: Platform * generation (Table 7). As a result, the intention to recommend should be interpreted within the interaction between these two factors, through the analysis of simple effects, which demonstrated that for the Airbnb platform, the intention of recommending was higher for generation $\mathrm{Z}$ than generation $\mathrm{X}(p=0.006)$, by between 0.07 and 0.94 points (Figure 1$)$. For the rest of the platforms, there was no demonstrable difference between generations for the intention of recommending. The intention of recommending was also higher for the experimental group, by between 0.93 and 1.52 points as compared to the control group $(p<0.0001)$.

Table 7. Model with FUT2 "Intention of recommending the service".

\begin{tabular}{ccccc}
\hline & Y Variable & Source & F Value & $p$ \\
\hline \multirow{2}{*}{ FUT2 } & Intention of recommending & PLATFORM & 4.40 & 0.006 \\
& & GROUP & 52.83 & 0.0001 \\
& & GENERATION & 5.38 & 0.022 \\
& SEX & 4.64 & 0.032 \\
& PLATFORM * GENERATION & 2.77 & 0.031 \\
\hline
\end{tabular}




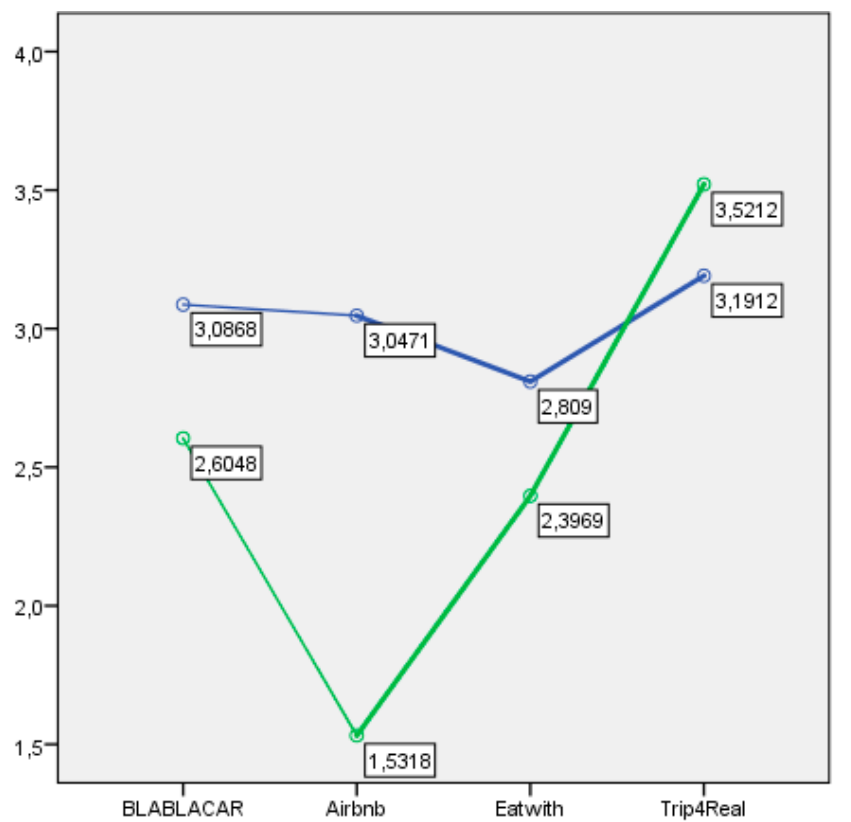

Figure 1. Intention of recommending means. Green line: X generation, Blue line: Y generation.

The sex variable demonstrates a link with FUT2. Women showed a higher intention of recommending some of the platforms $(t=2.37, p=0.02)$, between 0.07 and 0.74 points more.

This saturated factorial model maintains a first order interaction, PLATFORM * GROUP (Table 8). As such, the results should be interpreted by keeping in mind the interaction between the said variables, through an analysis of simple effects-an analysis of the differences between the groups of each platform. Within the simple effects, differences between the groups on the platform, Eatwith, can be observed (the experimental group shows a higher intention, 0.78 and 1.03 points, as opposed to the control group).

Table 8. Model with FUT4 "Intention/Possibility of being a provider/offering the service".

\begin{tabular}{ccccc}
\hline & Y Variable & Source & F Value & $p$ \\
\hline \multirow{2}{*}{ FUT4 } & Intention of providing_offering & PLATFORM & 3.06 & 0.03 \\
& & GROUP & 20.34 & 0.0001 \\
& & PLATFORM * GROUP & 3.53 & 0.016 \\
\hline
\end{tabular}

On the rest of the platforms, the differences were not significant, though overall there was a higher intention (Figure 2) of being a provider in the experimental groups; further, Trip4Real was, independent of the group, observably the platform for which the intention of being a provider was highest, though this effect depended on the significant interaction $(\mathrm{F}=3.53, p=0.016)$.

The final, saturated model collected the principal factors, PLATFORM and GROUP. GENERATION did not form a part of this model (Table 9). The model demonstrated that the intention-interest (future) in receiving information from one of the services varied according to the platform. It was higher for Trip4Real compared to BlaBlaCar $(p=0.001)$-between 0.24 and 1.41 points—and compared to Eatwith $(p=0.020)$ - between 0.08 and 1.48 points. The intention varied according to the group, and was higher with the experimental group with a goal $(p<0.0001)$, between 0.30 and 1 point higher as compared to the control group. 


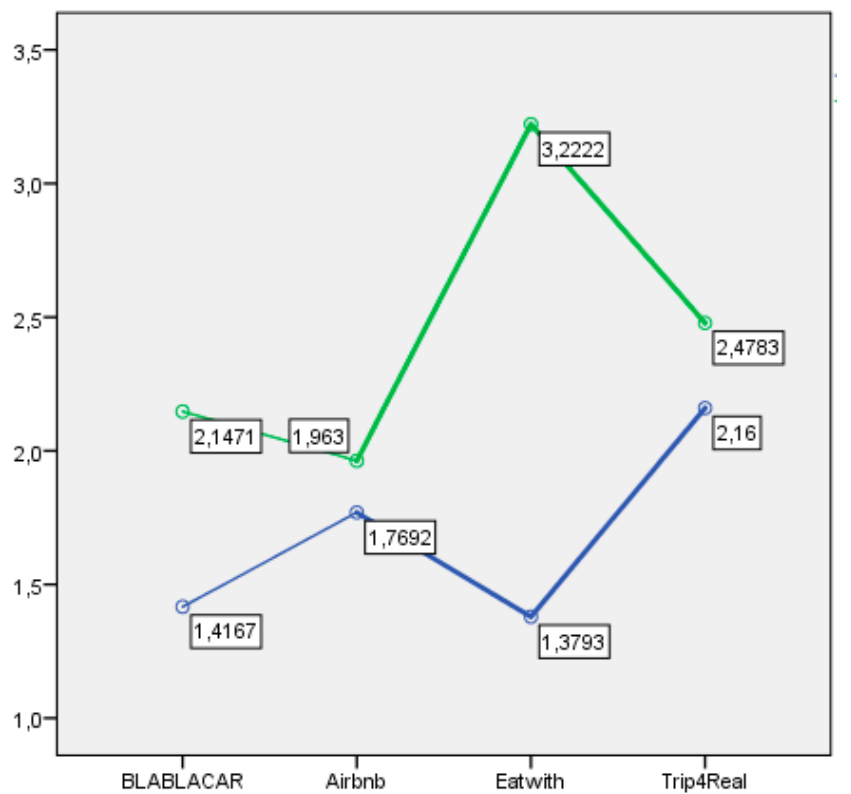

Figure 2. Intention of providing-offering means. Green line: experimental group, Blue line: control group.

Table 9. Model with FUT5 “Intention/interest in receiving information”.

\begin{tabular}{ccccc}
\hline & Y Variable & Source & F Value & $p$ \\
\hline \multirow{2}{*}{ FUT5 } & Intention-Interest in Receiving Information & PLATFORM & 4.35 & 0.005 \\
& & GROUP & 12.76 & 0.0001 \\
\hline
\end{tabular}

In terms of who participants recommended the platform to, respondents indicated that they recommended it to friends (39\%), to colleagues and family (5\% and 5\%, respectively), and to their entire circle of contacts (50\%).

Participants tended to respond that the services of the platforms were directed at people under 32 years of age (generation $\mathrm{Z}$ ) in the case of BlaBlaCar and Airbnb, and to Generation X in the case of Eatwith and Trip4Real $\left(X^{2}=25.22, p<0.0001\right)$.

About the psychometric properties of the scale, the nine scales or items for evaluation related to the current and future use of the platforms or CC services demonstrate, with Spearman's correlations, that the scales most frequently associated with future behavioral intentions-to use the platform again and to recommend it-were UTI2 (interest in using it) and to a lesser extent UTI3 (confidence-trust in the system). This indicates that these would be the strongest predictors. In terms of the remaining values, all of which were significant, they appeared within a range of 0.18 and 0.81 .

The combination of the scales demonstrates an internal consistency of 0.894 . The nine items were shown to be consistent (through Cronbach's alpha, if the deleted item showed a scores range of 0.87 to 0.89 , and the total corrected scores ranged from 0.52 to 0.82 ). As a result, the combined or global reliability of the scale is superior to the Nunnally (1978) criteria.

In PCA and factorial analysis with the oblimin rotation method (Table 10), the result demonstrates an adequate adjustment and capacity for the scale for undertaking the data reduction test, with a Kaiser-Meyer-Olkin value near $1(0.88)$, and a significant value for Bartlett's test $\left(X^{2}=1042.2\right.$, $p<0.0001$ ). 
Table 10. Factorial weights, oblimin rotation solution.

\begin{tabular}{ccc}
\hline & $\begin{array}{c}\text { Components } \\
\text { Evaluation-Intention }\end{array}$ & eWOM \\
\hline UTI2 & 0.862 & \\
UTI3 & 0.712 & \\
UTI4 & 0.504 & 0.857 \\
UTI5 & & 0.884 \\
UTI6 & & \\
FUT1 & 0.895 & \\
FUT2 & 0.861 & \\
FUT4 & 0.832 & \\
FUT5 & 0.507 & \\
\hline
\end{tabular}

The internal structure of the global scale-the nine items for evaluation-gives us a simple structure with two factors with individual values greater than 1 (5 and 1.2, respectively), with a total explained variability of $68 \%-55 \%$ due to the first factor and $13 \%$ to the second.

The first factor was comprised of all items of interest, confidence, use-value, and the behavioral intention-the intention of using the platform again and the intention of recommending it. The second factor was comprised of those items related to the eWOM or the online reputation, evidence of its importance, with its own identity, of the online comments-utility and intention of using the platforms as a prosumer.

In terms of the study's hypotheses:

H1: Was partially met. Generation Z only demonstrated significantly higher scores in the UTI3 scale (confidence when using the platform), in UTI5 (utility of the comments and evaluations online), and in FUT2 (interest in recommending, but only within the Airbnb platform).

H2: Was partially met. Higher scores were only noted for the participants from generation $\mathrm{Z}$ in relation to the utility of reading the comments-evaluations of the platforms, but not in leaving or making said comments-prosumer.

H3: Was met. The analysis of the principal components and factorial analysis demonstrated that both of the eWOM scales constitute individual factors, with a percentage of total explained variability of $13 \%$.

H4: Was partially met. Those belonging to the experimental group-those who were assigned a goal based on a fictional need-increased the scores on all scales, except the UTI5-use-value of the online comments-evaluations. There were higher scores for UTI2 (interest in using the platform), UTI3 (confidence-security in the service), UTI4 (confidence- security in the payment method), UTI6 (use-value of making/leaving online comments), FUT1 (intention of using the service again within the year), FUT2 (intention of recommending the service), FUT4 (intention of being a provider/offering the service, but only for Eatwith), and FUT5 (interest in receiving information).

\section{Discussion}

An analysis of the principal components and factorial analysis demonstrated the existence of two components or dimensions in a shared economy [2]: One that collects the interest, the confidence, and the intention to use, and the other that reflects the influence of eWOM on users, like in [11] and [22]. We should consider these difficulties in analyzing consumer behavior [27].

We demonstrated that any of the CC portals used in this study within the goal, based on a fictitious necessity, did exert an important influence on the judgements and evaluations, as well as on the intentions for future behavior-repeating the experience and recommending. It follows the pervasive effect ([21] and [22]). The experimental group had higher scores than the control group, with the exception of UTI5 - use-value of the online comments-evaluations-which was the same for both groups. In FUT4-intention of becoming a provider-offering the service- the said variable 
interacts with the platform, such that the results showed a greater intention for the experimental group only for the Eatwith platform.

Gender did not have a determining influence on the evaluations. There was only a significant difference between genders in FUT2-women demonstrated a higher intention of recommending the platforms. This could determine the use of these platforms $[7,8]$

\section{Conclusions}

In general, participants from generation $\mathrm{Z}$ (younger, millennials) obtained significantly higher scores only on the scales of UTI3 (confidence in using the platform), UTI5 (use-value of the comments-online evaluations), and FUT2 (interest in recommending, only the Airbnb platform). As a result, we believe that age or generation is not a key or crucial factor, given that there is data-at the level of use, connection to the Internet, and social networks [17]-that demonstrates that the use and inclination to use certain CC applications and portals is not exclusive to young people or to generation $\mathrm{Z}$.

The concepts of consumer and prosumer (consumers and designers of CC portals) within CC services are not exclusive to a single generation. Only in the level of utility of the online comments and evaluations was a higher score perceived, and this was not so in leaving/making comments.

The Trip4Real platform awakened a greater interest in use than BlaBlaCar, though these were similar to Airbnb and Eatwith. However, younger participants (generation Z) demonstrated a higher interest in recommending Airbnb, in the way of confidence [1]. For Eatwith, the experimental group (with a goal based on a necessity) demonstrated a higher intention of being providers or offering this service than the control group.

For interest in the desire to receive information on the platforms presented, Trip4Real was preferred to BlaBlacar and Eatwith. Thus, we could say that Trip4Real-or this type of service-awakens greater interest.

Regarding limitations, the sample, 220 participants, limits the strength of the tests. For further studies, larger samples, higher than 500 participants, would be advised. The scales from 1 to 5 show a limited variability, which means that in the majority of the tests for relationships, such as the MANOVA tests that were undertaken, there was a lack of homogeneity between variances, such that for these cases, a conservative or corrected F was used in the calculation of the degree of significance. At the same time, this lack of variability, and the use of ordinal type scales, means that non-parametric correlations are advised. We believe that for scales with a greater range, from 0 to 10 , the types of problems related to scales with a reduced range can be mitigated.

For future research, we suggest a longitudinal analysis of the selected collaborative consumption platforms, and the inclusion of other new platforms, in diverse countries or continents or focused on specific enterprises [23]. This research could provide insights into the identified platforms to improve their relationship with the end user, and to obtain more engagement with the prosumer.

Author Contributions: Conceptualization, J.-F.F.-G., G.B. and M.M.-G.; Methodology, J.-F.F.-G. and G.B.; Software, J.-F.F.-G. and G.B.; Validation, J.-F.F.-G., G.B. and M.M.-G.; Formal Analysis, J.-F.F.-G.; Investigation, J.-F.F.-G. and G.B.; Resources, J.-F.F.-G. and G.B.; Data Curation, J.-F.F.-G. and G.B.; Writing-Original Draft Preparation, J.-F.F.-G. and G.B.; Writing-Review and Editing, J.-F.F.-G.; Visualization, J.-F.F.-G.; Supervision, J.-F.F.-G.; Project Administration, J.-F.F.-G. and M.M.-G.; Funding Acquisition, J.-F.F.-G.

Funding: This research was funded by Generalitat de Catalunya, grant SIMPED.

Conflicts of Interest: The authors declare no conflict of interest.

\section{References}

1. Botsman, R.; Rogers, R. What's Mine Is Yours: The Rise of Collaborative Consumption; Harper Business: New York, NY, USA, 2010.

2. Gerstner, L. Cash In on the Sharing Economy. Kiplinger's Pers. Financ. 2014, 68, 58-60. 
3. Rifkin, J. La sociedad de coste marginal cero: El Internet de las cosas, el procomún colaborativo y el eclipse del capitalism; Paidós: Barcelona, Spain, 2014.

4. Cañigeral, A. Innovación en modelos socio- económicos. Introducción al Consumo Colaborativo; Scridb: Madrid, Spain, 2012.

5. Armas, R.J.D.; Taño, D.G.; García Rodríguez, F.J. Airbnb como nuevo modelo de negocio disruptivo en la empresa turística: Un análisis de su potencial competitivo a partir de las opiniones de los usuarios. Benidorm: XVIII Congreso AECIT. 2014. Available online: https://www.researchgate.net/publication/ 270394571_Airbnb_como_nuevo_modelo_de_negocio_disruptivo_en_la_empresa_turistica_un_analisis_ de_su_potencial_competitivo_a_partir_de_las_opiniones_de_los_usuarios (accessed on 17 September 2018).

6. Fondevila-Gascón, J.-F. La adaptación regulatoria de los operadores de cable histórico en España. La competencia de los grandes operadores. Telos. Cuadernos de Comunicación e Innovación 2009, 80, 139-146.

7. Fondevila-Gascón, J.-F. El peso de la televisión en el triple play de los operadores de cable en España y en Europa. J. Commun. Stud. 2009, 14, 13-31.

8. Fondevila-Gascón, J.-F. La televisión conectada: Ventajas e inconvenientes del estándar HbbTV. Cuadernos de Información 2012, 32, 11-20. [CrossRef]

9. Fondevila-Gascón, J.-F.; Berbel, G.; Muñoz, M.; Mir, P.; Puiggròs, E. Using smartphones reservations for hotels in Barcelona for a business segment: Empirical analysis. Global J. Comput. Sci. 2015, 5, 60-67. [CrossRef]

10. Fondevila-Gascón, J.-F.; Carreras-Alcalde, M.; Seebach, S.; Pesqueira-Zamora, M.J. How Elders Evaluate Apps-A Contribution to the Study of Smartphones and to the Analysis of the Usefulness and Accessibility of ICTS for Older Adults. Mob. Media Commun. 2015, 3, 250-266. [CrossRef]

11. IAB. VII Estudio Redes Sociales de IAB Spain; Interactive Advertising Bureau: Madrid, Spain, 2016. Available online: http:/ / www.iabspain.net/wp-content/uploads/downloads/2016/04/IAB_EstudioRedesSociales_ 2016_VCorta.pdf (accessed on 18 September 2018).

12. Hei, X.; Liang, C.; Liang, J.; Liu, Y.; Ross, K.W. A Measurement Study of a Large-Scale P2P IPTV System. IEEE Trans. Multimedia 2007, 9, 1672-1687.

13. Montresor, A.; Jelasity, M. PeerSim: A scalable P2P simulator. In Proceedings of the 2009 IEEE Ninth International Conference on Peer-to-Peer Computing, Seattle, WA, USA, 8-11 September 2009.

14. Pizam, A. Peer-to-peer travel: Blessing or blight? Int. J. Hosp. Manag. 2014, 38, 118-119. [CrossRef]

15. Fondevila-Gascón, J.-F.; Mir-Bernal, P.; Rom-Rodríguez, J.; Santana-López, E.; Botey-López, J. El factor reputacional y los medios sociales: Propuestas métricas comparadas (699-714). In Redes Sociales y lo 2.0 y 3.0; Juan Enrique Gonzálvez and Mónica Valderrama (Coords.): Madrid, Spain, 2015.

16. Gretzel, U. Consumer generated content. Trends and implications for branding. E-Rev. Tour. Res. 2006, 4, 9-11.

17. Gretzel, U.; Yoo, K. Use and impact of online travel reviews. In Information and Communication Technologies in Tourism; O'Connor, P., Höpken, W., Gretzel, U., Eds.; Springer: New York, NY, USA, 2008; pp. 35-46.

18. Pan, B.; MacLaurin, T.; Crotts, J.C. Travel blogs and the implications for destination marketing. J. Travel Res. 2007, 46, 35-45. [CrossRef]

19. Xiang, Z.; Gretzel, U. Role of social media in online travel information search. Tour. Manag. 2010, 31, $179-188$. [CrossRef]

20. Cheng, V.T.P.; Loi, M.K. Handling negative online customer reviews: The effects of elaboration likelihood model and distributive justice. J. Travel Tour. Mark. 2014, 31, 1-15. [CrossRef]

21. Xie, K.; Zhangb, Z.; Zhangb, Z. The business value of online consumer reviews and management response to hotel performance. Int. J. Hosp. Manag. 2014, 43, 1-12. [CrossRef]

22. OCU. Estudio sobre consumo colaborativo; OCU: Madrid, Spain, 2015. Available online: https:// prosalus.es / es/noticias/estudio-sobre-consumo-colaborativo (accessed on 8 September 2018).

23. Wang, T.; Kanliang, L.O. User Adoption and Purchasing Intention after Free Trial: An Empirical Study of Mobile Newspapers. 2013, pp. 189-210. Available online: http:/ / doi.org/10.1007/s10257-012-0197-5 (accessed on 15 December 2018).

24. Bhattacherjee, A.; Sanford, C. Influence processes for information technology acceptance: An elaboration likelihood model. MIS Q. 2006, 30, 805-825. [CrossRef]

25. Hong, S.-J.; Thong, J.Y.L.; Moon, J.-Y.; Tam, K.-Y. Understanding the behavior of mobile data services consumers. Inf. Syst. Front. 2008, 10, 431-445. [CrossRef] 
26. Thong, J.Y.L.; Hong, S.J.; Tam, K.Y. The effects of post-adoption beliefs on the expectation confirmation model for information technology continuance. Int. J. Hum. Comput. Stud. 2006, 64, 799-810. [CrossRef]

27. Festinger, L.A. A Theory of cognitive dissonance; Stanford University Press: Redwood City, CA, USA, 1957.

28. Bhattacherjee, A.; Premkumar, G. Understanding changes in belief and attitude toward information technology usage: A theoretical model and longitudinal test. MIS Q. 2004, 28, 229-254. [CrossRef] 